\title{
0 clima como necessidade de governança transnacional: reflexões pós-Copenhague 2009
}

\author{
Paulo Márcio Cruz ${ }^{1}$ \\ Zenildo Bodnar ${ }^{2}$
}

\begin{abstract}
Resumo: O presente artigo aborda a questão climática analisada sob a ótica da governança transnacional como necessidade para enfrentar os desafios pós XV Conferência da Mudança do Clima da ONU (COP 15), Copenhague 2009. Parte-se da hipótese de que não é possível o estabelecimento de uma política regulatória efetiva para a questão climática que não leve em conta a governança transnacional, entendida esta como forma de articulação entre o poder local e o global, baseada na cooperação e na solidariedade.
\end{abstract}

Palavras-chave: Transnacionalidade. XV Conferência da mudança do Clima da ONU. Governança transnacional.

\begin{abstract}
This article analyzes climate changes from the perspective of transnational governance and the need to face the challenges found after UN Climate Change Conference, Copenhagen, 2009. It starts with the assumption that it is not possible to establish an effective regulatory policy for the climate if it does not take into account the transnational governance, which is understood as an articulation between local and global powers, based on cooperation and solidarity.
\end{abstract}

Keywords: Transnationality. XV UN Climate change conference. Transnational governance.

1 Realizou estágio pós-doutoral em Direito do Estado na Universidade de Alicante, Espanha; doutor em Direito do Estado pela Universidade Federal de Santa Catarina e mestre em Instituições Jurídico-Políticas também pela Universidade Federal de Santa Catarina - UFSC. Coordenador e professor do Programa de Pós-Graduação Stricto Sensu em Ciência Jurídica da Universidade do Vale do Itajaí - UNIVALI em seus programas de doutorado e mestrado em Ciência Jurídica. Foi Secretário de Estado em Santa Catarina e Vice-Reitor da UNIVALI. É professor visitante nas universidades de Alicante, na Espanha e de Perugia, na Itália. E-mail: pcruz@univali.br.

2 Doutor em Direito pela Universidade Federal de Santa Catarina, mestre em Ciência Jurídica pela Universidade do Vale do Itajaí. Realizou estágio pós-doutoral pela Universidade Federal de Santa Catarina - UFSC. Juiz Federal da Vara Ambiental de Florianópolis/SC. Professor do Programa de Pós-Graduação Stricto Sensu em Ciência Jurídica da Universidade do Vale do Itajaí - UNIVALI em seus programas de doutorado e mestrado em Ciência Jurídica. Pesquisador do CNPQ. E-mail: zenildo@univali.br. 


\section{Introdução}

Através da participação no Projeto Jean Monnet, denominado “Direito da União Europeia e Transnacionalidade”, em colaboração com a Universidade do Minho, com foco no que vimos escrevendo sobre transnacionalidade e a necessidade de uma nova construção teórica para abrigar as relações jurídicas globalizadas, no final de 2009 resolvemos analisar a XV Conferência da Mudança do Clima da ONU (COP15), realizada em Copenhague e cujos resultados - ou a falta deles - ensejam intensos debates. Parece-nos evidente que, sem uma nova conformação para as relações jurídicas globais - que chamamos de transnacionais, como o leitor verá ao longo deste artigo - não será possível avançar com a intensidade, abrangência e consistência necessárias para um tema mais que vital como é o clima.

É nesse sentido que se manifesta Aron Belinky, ${ }^{3}$ quando denuncia a limitação das instituições baseadas na lógica dos Estados nacionais “enclausurados em suas soberanias”, já que a crise da representatividade dos Estados nacionais e dos políticos que os dirigem é gritante em todo o mundo. Para ele, a necessidade de instituições verdadeiramente transnacionais é evidente. Ele diz que, antes, não tínhamos receio de desbravar o mundo. Hoje estamos aprendendo a viver numa nave lotada e de recursos restritos. Segundo ele, o caminho para enfrentarmos as “enrascadas” globais passa pelo nascimento de uma cidadania planetária, superando-se o acordo conhecido como paz da Vestfália.

Belinky é enfático ao afirmar que o sistema internacional não é transnacional, pois apenas junta países que continuam encalacrados em suas agendas nacionais. E conclui que "o atual cenário aponta para que se construam espaços de cooperação e articulação transnacionais”. A

\footnotetext{
3 Aron Belinky é especialista em desenvolvimento sustentável, tendo participado da criação da Fundação SOS Mata Atlântica e do Núcleo Pró-Jureia da Sociedade de Defesa do Litoral Brasileiro, que dirigiu entre 1986 e 1991. Consultor e especialista em Responsabilidade Social e Sustentabilidade Socioambiental, representante das ONGs de países em desenvolvimento no comitê redator da ISSO 26000. É um dos principais teóricos que percebeu a necessidade de juridicização transnacional.
} 
crise financeira é um exemplo de que não se pode deixar a globalização confiada “à mão invisível do mercado” (BELINKI, 2009, p. 30).

A reflexão teórica aqui apresentada sustenta-se em duas justificativas ou razões fundamentais. A primeira decorre da própria sensibilização global para o problema do clima em função da falta de metas de controle de emissões de gases pelos Estados, e da extrema necessidade de um novo e amplo acordo global a respeito da matéria. A segunda, da ausência do alcance pleno dos objetivos idealizados e esperados na XV Conferência da Mudança do Clima da ONU (COP15).

A avaliação geral, logo após o encerramento do evento, foi que o encontro da Dinamarca representou, ao que tudo indica, um grande fracasso. Na opinião de representantes de países emergentes e europeus, a crise de confiança foi provocada pela apresentação inoportuna de uma proposta unilateral, estimulada pelos Estados Unidos logo no início da conferência.

Depois de dias de trabalho, a declaração resultante da XV Conferência da Mudança do Clima da ONU (COP15) acabou por não estabelecer metas claras de corte na emissão de gases geradores do efeito estufa. E, genericamente, falou-se de um fundo de U\$ 100 bilhões sem precisar de onde viria o dinheiro e nem de como ele seria usado.

Segundo os especialistas, os impasses criados em Copenhague giraram especialmente em torno da disputa entre países ricos e pobres. O Protocolo de Kyoto, de 1997, estabeleceu obrigações de emissões somente aos países ricos. Esses, porém, querem que os países emergentes também assumam responsabilidades no que diz respeito, por exemplo, às contribuições para a formação deste "fundo climático”. Algumas questões chamaram a atenção especificamente. O Presidente Americano Barack Obama, durante todo o tempo em que esteve em Copenhague, falou em acordo "que será legalmente vinculante, mas que cada país ensinará ao mundo o que está fazendo”. Entretanto, em momento algum foi explicado como se faria essa vinculação obrigatória, já que se sabe que o Direito Internacional é limitado por sua própria essência no que diz respeito à sua capacidade coercitiva. A questão de um acordo legalmente vinculante contra um 
compromisso meramente político converteu-se no último obstáculo a ser superado nas negociações climáticas.

Um acordo juridicamente vinculante seria importante por muitas razões. Para começar, um resultado desse tipo aumentaria a confiança e aproximaria posições entre os países industrializados e as economias em transição.

Na maioria dos casos, a desconfiança entre os países dos dois grupos, tecnicamente chamados de "países do anexo I” e "países não anexo II" deve-se à falta de cumprimento de compromissos assumidos pelos dois grupos em função da debilidade do sistema de direito internacional.

Neste contexto, o presente artigo procura demonstrar que a ausência dos parâmetros da transnacionalidade, nas perspectivas política e jurídica, contribuiu decisivamente para que a XV Conferência da Mudança do Clima da ONU (COP15) não representasse significativo avanço em relação ao Protocolo de Kyoto.

As reflexões articuladas neste texto objetivaram caracterizar o clima enquanto uma demanda transnacional e a transnacionalidade enquanto estratégia política e jurídica de governança. Também tiveram como alvo avaliar a possibilidade de utilização da concepção teórica da transnacionalidade, enquanto critério político e jurídico de regulação das pautas de condutas dos Estados para o alcance de objetivos e metas relativas à emissão de poluentes causadoras do aquecimento global.

\section{O clima como demanda transnacional}

As lesões ao ambiente afetam a coletividade, perpassam fronteiras, alteram o equilíbrio climático, atingem a atual e as futuras gerações e toda a comunidade de vida e definitivamente não respeitam os limites territoriais dos Estados.

A principal característica da questão vital ambiental ${ }^{4}$ está na sua perspectiva global transnacional. Considerando a forma pela qual os

4 Utiliza-se a expressão “questão vital ambiental” para sugerir que a base axiológica formadora dos ordenamentos jurídicos transnacionais seria a proteção aos bens ambientais, 
ecossistemas se relacionam e a vida acontece e se desenvolve em todo o planeta, é manifestadamente impossível implementar uma tutela efetiva restrita a determinado país ou território, baseada no superado conceito moderno de soberania.

Nesse sentido, Loporeta Rota indica que a questão ambiental apresenta vocação espacialmente planetária e denuncia que a organização da sociedade humana em Estados, pretensamente soberanos, faz com que o âmbito de aplicação das suas normas seja restrito aos limites das suas fronteiras (LOPORETA ROTA, 1998, p. 27-28). Tal configuração não é apropriada para a questão ambiental, já que o objeto sobre o que se projeta é insuscetível de submeter-se às caprichosas linhas dos Estados nacionais. A proteção da biosfera não é, portanto, compatível com este esquema e tampouco os ordenamentos jurídicos nacionais e internacionais que pretendem protegê-la, pois faltam ferramentas comuns a todos os cidadãos e países. ${ }^{5}$

Numa perspectiva ecológica, são evidentes as atuais limitações decorrentes da ordenação das esferas de poder, coerção, fomento e gestão. Sílvia Jaquenod (2008, p. 6) acompanha Francisco Días Pineda, Catedrático de Ecologia da Universidade de Madrid, quando explica que os sistemas naturais, e praticamente todos os sistemas culturais, têm pouco a ver com a delimitação de fronteiras em um mapa, pois o ciclo da água, a dinâmica do ar ou os movimentos migratórios biológicos e como consequência o clima não entendem de fronteiras.

entendidos em dimensão ampla, inclusive contemplando o aspecto social. Assim, estarse-ia também tutelando a dignidade da pessoa humana, já que um dos maiores problemas ambientais da humanidade é a fome e a miséria.

5 Martín Mateo (1997, p. 58) aponta que é exatamente a disposição institucional em parcelar a terra em estados soberanos que inviabiliza o estabelecimento de uma ordem mundial coerente para sistemas naturais intrinsecamente planetários. Nesta mesma linha, Leff (2005, p. 31) explica que hoje o conceito de ambiente se defronta com estratégias de globalização e que a reinvenção do mundo (conformado por uma diversidade de mundos) passa pelo estabelecimento de ordem econômico-ecológica globalizada. No mesmo sentido, Silvia Jaquenod de Zsögön (2008. p. 207) destaca a necessidade de novos limites geopolíticos para a governança dos recursos naturais, enfatizando que a posição baseada na cooperação e no compartilhamento supera a situação real entre Estados. 
Martín Mateo (2002, p. 54, 73) é categórico ao afirmar que a biosfera é única, inter-relacionada e olimpicamente alheia às jurisdições nacionais e zelosas soberanias. Para o professor catedrático da Universidade de Alicante, o direito ao qual estamos familiarizados é de âmbito nacional, emana de organizações peculiares com limites físicos rígidos e plotados nas fronteiras do território em que se exerce a soberania. Todavia, os sistemas ambientais tendem a ser indefinidamente transnacionais e, portanto, ignoram olimpicamente a geografia política interior.

Também é assim para o italiano Giovanni Cordini, quando assinala que a salvaguarda do ambiente poderá ser assegurada de forma mais eficiente se a tutela for sempre mais ampla do que as fronteiras do Estado singular, por intermédio dos poderes do governo e da jurisdição que ultrapassem os limites da soberania estatal (CORDINI, 1997, p. 7).

Desta forma, como corolário, é importante registrar que a preocupação com o clima, tema que levou a ONU a realizar a recente Convenção em Copenhague, é indiscutivelmente transnacional e deve interessar indistintamente a todos os habitantes do planeta, independentemente da sua condição social, econômica e do patamar de desenvolvimento.

A preocupação com o equilíbrio climático é sem dúvida uma pauta axiológica comum transnacional de extrema e prioritária relevância na atualidade, pois já na primeira frase da Convenção-Quadro das Nações Unidas $^{6}$ foi consignado enfaticamente que a mudança do clima da Terra e seus efeitos negativos são uma preocupação comum da humanidade.

Todos esses aspectos até aqui tratados, e uma vez caracterizada a questão climática como uma demanda transnacional, evidenciam a necessidade da superação da lógica das relações internacionais, baseada na criação de regras bilaterais ou multilaterais, ${ }^{7}$ e destituídas de real

6 A Convenção-Quadro das Nações Unidas foi o principal acordo já firmado sobre a questão climática. Foi assinada por mais de 150 países no Rio de Janeiro na cúpula da terra em 1992 (ECO 92).

7 Como exemplo de tutela de bens ambientais verdadeiramente planetários, pela lógica do Direito Internacional Clássico, cite-se a Convenção de Ransar que estabelece cooperação internacional para proteção de áreas úmidas situadas nas zonas fronteiriças, por intermédio de acordos interestatais. Dentre os acordos celebrados, citem-se os 
juridicidade concreta e efetividade por não vincularem diretamente os potenciais e principais degradadores, mas apenas os Estados contratantes.

\section{Transnacionalidade e ambiente}

Como já exaustivamente registrado, as mudanças climáticas são fruto, principalmente, do processo de industrialização experimentado no Século XX e da intensa globalização econômica, característica desse início de Século XXI, coadjuvados pela concentração de riqueza em alguns nos países desenvolvidos e a consequente pobreza endêmica vivida em mais da metade do planeta.

Pode-se dizer que a Era do Petróleo, que coincide com os processos de industrialização de inspiração "fordista”, foi o grande divisor de águas em termos de desequilíbrio climático. Essa matriz energética deverá ser substituída ao longo do Século XXI.

Com o fim da União Soviética, em 1989 (CRUZ, 2009, p. 17), a liberalização do mercado mundial progrediu muito, como escreve Habermas (2001, p. 47). A mobilidade do capital acelerou e o sistema industrial foi modificado, saindo da produção de massa e passando a adequar-se às necessidades da "flexibilidade pós-fordista". Com os mercados cada vez mais globalizados, o equilíbrio alterou-se, prejudicando claramente a autonomia e a capacidade de ação político-econômica dos Estados constitucionais modernos, que afinal são os responsáveis pelas medidas de contenção às agressões ao meio ambiente.

Mas as estruturas governativas nacionais não conseguem mais dar respostas consistentes e eficazes diante da complexidade das demandas transnacionais que se avolumam continuamente. Os problemas sociais também aumentam em proporções preocupantes.

As relações internacionais possibilitadas pelo Direito Internacional - mesmo considerando a criação de novas estruturas e organizações

seguintes ecossistemas: a) Parque Transfronteiriço Lagos de Prespa (Albânia, Grécia e Ex República Yuguslava da Macedônia); b) Polisie (Bielorússia, Polônia e Ucrânia); c) Vallé de la Haute-Súre, criado pela Bélgica e Luxemburgo, dentre outros. 
interestatais - são incapazes de gerar mecanismos eficazes de governança, regulação, intervenção e coerção para as demandas transnacionais. Esse fenômeno é muito bem observado quando se trata do ambiente, em especial da questão climática.

Para um efetivo enfrentamento dos problemas climáticos, é preciso que o tratamento político e jurídico possa ser proposto a partir de um ou mais espaços públicos transnacionais, ou seja, da criação de espaços públicos que possam perpassar Estados nacionais.

Nesse sentido, o prefixo trans indica que a estrutura pública transnacional pode perpassar vários Estados. Desde logo, convém advertir que não se está falando de Estado mundial ou de um superestado. O que se está levando à discussão é a possibilidade/necessidade de fundação de um ou vários espaços públicos de governança, regulação e intervenção, ${ }^{8}$ cujos mecanismos de controle e funcionamento sejam submetidos às sociedades transnacionalizadas.

O prefixo trans denota ainda a capacidade não apenas da justaposição de instituições ou da superação/transposição de espaços territoriais, mas a possibilidade da emergência de novas instituições multidimensionais, objetivando a produção de respostas mais satisfatórias aos fenômenos globais contemporâneos, como é o caso dos relativos ao ambiente e ao clima.

A expressão latina trans, aplicada a questões como o clima e outras demandas difusas transnacionais ${ }^{9}$ significa algo que vai “além de” ou “para além de”, a fim de evidenciar a superação de um locus determinado, que indica que são perpassadas diversas categorias unitárias, num constante fenômeno de desconstrução e construção de significados.

8 Intervenção, no contexto deste artigo, significa o controle pelo Estado, em graus variados, através de atuação, como parte ativa, nos âmbitos ambiental, social econômico e cultural para garantir padrões mínimos de dignidade humana a partir de pauta axiológica comum. Já a categoria Regulação, tem o sentido de fornecer à Sociedade, através do Estado, regras que regulem as relações públicas e privadas, evitando desequilíbrios, sem que o governo seja parte ativa em qualquer delas.

9 Dentre as demandas transnacionais também podem ser citados os Direitos Humanos, a segurança, a atual ordem econômica global, a criminalidade transnacional, dentre outras. 
Diversamente da expressão inter, a qual sugere a ideia de uma relação de diferença ou apropriação de significados relacionados, o prefixo trans denota a emergência de um novo significado construído reflexivamente a partir da transferência e transformação dos espaços e modelos nacionais.

É como Ulrich Beck (2001, p. 100) manifesta-se ao escrever que a transnacionalização é uma conexão forte entre os espaços nacionais. Inclusive de modo que não seja pensado internacionalmente, e sim no surgimento de algo novo, de um espaço transpassante, que já não se encaixa nas velhas categorias modernas. Essa percepção, quando se trata de ambiente e clima, é fundamental.

A nova ordem mundial, influenciada por diversos fatores decorrentes da intensificação do fenômeno da globalização, torna oportuna e necessária a discussão sobre a organização de espaços públicos transnacionais que viabilizem a democratização das relações entre Estados, fundadas na cooperação e na solidariedade, com o intuito de assegurar a construção das bases e estratégias para a governança, regulação e intervenção transnacionais.

No mesmo diapasão, Tomas Villasante (2003, p. 63) sugere que a “internalização” do Poder Público da modernidade cederá passo ao processo de transnacionalização do Poder Público. Caso contrário, a debilidade do Estado Constitucional Moderno poderá conduzir a civilização a perigosas posições de confronto.

A partir dessas reflexões, pode-se caracterizar a existência de espaços jurídicos transnacionais como sendo a emergência de novos conceitos democráticos de solidariedade e cooperação, livres das amarras ideológicas da modernidade. Esse novo espaço público é decorrente da intensificação da complexidade das relações globais, deve ser dotado de capacidade jurídica de governança, regulação, intervenção e coerção, e ter com o objetivo projetar a construção de um novo pacto de civilização mais atento e sensibilizado com as questões ecológicas globais.

É o que propõe Gabriel Real Ferrer (2002, p. 73, 93), quando assinala que não se trata de estabelecer uma república planetária, mas sim da busca de mecanismos institucionais que assegurem a eficaz 
materialização da solidariedade, no mesmo diapasão de inspiração de novos direitos transnacionais, como é o caso do Direito Ambiental. Cada espaço jurídico transnacional poderá abranger vários Estados e até partes aderentes dos mesmos, com estruturas de poder cooperativo e solidário.

Um trabalho científico muito importante que aborda também os desafios da governança na perspectiva da Transnacionalidade foi elaborado pelo Professor Americano Oran R. Young. Neste ensaio, explica que o estudo dos regimes internacionais ganhou força ao fundir-se com o novo institucionalismo, consolidando a concepção de governança como função social centrada em dirigir os sistemas sociais de forma a aumentar o bem-estar das populações. Esclarece que essa teorização não exclui a possibilidade de ilhas de governança para questões específicas. Reconhece que a teoria do regime deve ter como ponto de partida que as estratégias de governança são criadas para responder à demanda de governo em uma sociedade, e que os Estados ainda são atores essenciais. ${ }^{10}$

Seus objetivos seriam os de proporcionar, nesses espaços transnacionais de governança, condições para que a globalização esteja submetida ao interesse da maioria das sociedades existentes, a partir de práticas de deliberação por consenso ${ }^{11}$ e de participação democráticas.

Uma das maiores justificativas para a construção de espaços públicos transnacionais diz respeito à questão vital ambiental, ${ }^{12}$ na qual o clima está incluído, que poderá ocupar o papel de "tela de fundo” para a construção desses espaços jurídicos transnacionais.

Ou seja, a estruturalização constitucionalizada, destinada a garantir o mínimo de segurança jurídica e típica do Estado Constitucional

\footnotetext{
10 Cf. Oran R.Young: Teoria do regime e a busca de governança global (VARELLA; BARROS-PLATIAU, 2009, p. 221-223).

11 A busca pelo consenso nas deliberações tem sido um dos principais elementos de manutenção, aprimoramento e ampliação dos institutos da União Europeia, assim como a Organização Mundial do Comércio (OMC).

12 Sobre isso, ver o artigo denominado La transnacionalidad y la emergencia del Estado y del Derecho Transnacionales (CRUZ; BODNAR, 2009).
} 
Moderno, seria superada pela questão vital ambiental como paradigma e que matizará o ordenamento jurídico transnacional.

Desde esse ponto de vista, Arnaldo Miglino (2007), em artigo denominado Una comunitá mondiale per la tutela dell'ambiente, afirma que existe um problema que provavelmente levará à criação de um centro de poder transnacional que supere a ideologia e a estrutura jurídica das relações internacionais: o problema ecológico. Basta recordar como a emissão ilimitada de gases geradores de efeito estufa (dióxido de carbono, óxido nitroso, metano, perfluorcarbonetos, hidrofluorcarbonetos, hexafluoreto de enxofre) contribuiu decisivamente com o aquecimento climático global, para compreender como é urgente a necessidade de instrumentos regulatórios transnacionais para restaurar o equilíbrio ecológico e climático.

Como exemplo de prática jurídica transnacional, e que muito bem ilustra o que vem sendo proposto neste trabalho, podem-se citar as convenções que versam sobre a proteção global da questão do ambiente, em especial a EC0/92, elaborada no Rio de Janeiro. ${ }^{13}$ Trata-se de um dos mais completos e abrangentes instrumentos destinados à proteção de bem jurídico transnacional que, apesar da sua notável qualidade propositiva, tem se mostrado extremamente deficiente na sua implementação em nível global por falta de capacidade cogente, ou seja, de institutos capazes de tornar concreta a sua aplicação como norma jurídica.

Exatamente essa deficiência, ou seja, a falta de mínima força cogente, também se observa nos tratados e acordos celebrados em relação à questão climática.

Considerando-se que toda organização supõe um ordenamento ou conjunto de normas coordenadas que tornam possível sua própria existência e funcionamento, o ordenamento jurídico transnacional dificilmente não acompanhará essa lógica.

13 A Eco/92 foi a maior conferência mundial sobre meio ambiente realizada para tratar da proteção do meio ambiente e desenvolvimento sustentável. Nessa conferência foram provados os princípios e diretrizes a serem observadas em escala global. 
O ordenamento jurídico transnacional poderá apresentar características próprias, destinado a atuar em espaço de governança regulatória e de intervenção até agora não organizado politicamente.

Isso porque, a partir da hegemonia capitalista, principalmente depois da queda do muro de Berlim em 1989, que é seu principal ponto de inferência conforme já assinalado, é indiscutível a existência de um novo poder. Este novo poder, que é basicamente econômico, mas também transita em territórios políticos e sociológicos, acontece no espaço despolitizado, desterritorializado, desregulamentado, e não sujeito a qualquer tipo de direito.

Oportuno assinalar que nos tempos atuais o capitalismo “desterritorializado” não se submete ao interesse geral ou da maioria. Isso impede também que temas como meio ambiente estejam submetidos ao interesse da maioria. Algo como uma transnacionalização republicana (CRUZ; CADEMARTORI, 2009, p. 90), ou a republicanização da globalização.

A XV Conferência da Mudança do Clima da ONU (COP15), deixou de organizar a necessária discussão política e de criar um ambiente receptivo ao amplo consenso sobre esse novo poder transnacional. Com isso, acabou por protelar a possibilidade da emergência de um novo direito, que a doutrina atual convencionou chamar de direito transnacional. É um figurino clássico que pode ser aplicado ao atual cenário mundial: a existência de um poder não limitado, a necessidade da politização da discussão sobre esse poder e a consequente criação de um direito que o limite.

Na prática, a validade de todo o sistema jurídico transnacional depende da sua vinculação - formal e material - à existência de ordenamento jurídico transnacional, que definirá tanto os valores e decisões básicas do ordenamento, como o sistema de criação e aplicação das normas que o integrarão, a partir principalmente da formação ampla do consenso.

O sistema jurídico transnacional será matizado pela necessidade da emergência de novos espaços públicos que tornarão concretas e efetivas as estratégias transnacionais de governança, regulação e intervenção, 
e que resultarão em proteção a direitos transnacionais baseados em pauta axiológica comum, em especial os difusos, impossíveis de serem alcançados pelos direitos nacional, comunitário e internacional, hoje existentes.

Não se pode imaginar medidas efetivas para a proteção e recuperação do ambiente, o que é fundamental para qualquer iniciativa com relação ao clima, sem essa nova maneira de enxergar as relações entre os Estados nacionais, baseada na cooperação e na solidariedade em espaços de governança para temas específicos, como é o caso do ambiente e do clima.

\section{Governança transnacional e a questão do clima}

As novas demandas transnacionais, a exemplo da questão climática, caracterizam um cenário extremamente receptivo para a emergência de novas instituições políticas e jurídicas que sejam capazes de agregar e articular atitudes solidárias e cooperativas e envolver pessoas e Estados na luta pela proteção de bens e valores imprescindíveis para assegurar a vida plena e duradoura no planeta. ${ }^{14}$

Segundo Philippe Le Prestre e Benoit Matimort-Asso, hoje, o tema de governança alcançou especial importância pela expansão da ação internacional, pela problemática da governança dos bens comunais mundiais e dos bens públicos mundiais, bem como pelo forte conteúdo técnico e econômico de muitos acordos multilaterais, em especial envolvendo o tema do meio ambiente. ${ }^{15}$

A grande diferença qualitativa de uma governança internacional para novas estratégias de governança transnacional está exatamente na forma de articulação entre o poder local e o global, ou seja, não é possível

14 Michel Bachelet (1995, p. 19) é enfático ao afirmar que: “A menos que a Sociedade internacional aperfeiçoee, sobretudo, aplique as normas deuma Solidariedademultissetorial à escala de todos os habitantes do planeta, populações inteiras desaparecerão pura e simplesmente pelos efeitos conjugados da SIDA e dos jogos da economia mundial”.

15 Cf. Le Prestre e Martimort-Asso: A reforma na governança internacional do meio ambiente: os elementos do debate (VARELLA; BARROS-PLATIAU, 2009, p. 238). 
prescindir da indispensável parceria cooperativa das esferas locais de poder; ao mesmo tempo, é necessário multiplicar os esforços locais para a produção dos melhores resultados em escala global.

Considerando a amplitude e a complexidade das novas demandas, as novas estratégias de governança devem ter como pressupostos: a aproximação entre povos e culturas; a participação consciente e reflexiva do cidadão na gestão política, econômica e social.

A emergência de novas formas de governança e de produção do direito não pode ser uma imposição decorrente da vitória do mais forte; ${ }^{16}$ deve ser sim o resultado da emancipação de valores, posições jurídicas e subjetividades esquecidas, fragilizadas e em situação de risco manifesto, como é o caso da questão climática.

A cooperação e a solidariedade devem ser os princípios estruturantes da governança climática. Isso porque a sensação de pertencimento de todos os cidadãos do planeta é e deve ser global. É fundamental que sejam superadas as formas individualistas de viver, de conceber e perceber o próximo, e também as formas de agir dos Estados Constitucionais Modernos baseados em princípios e valores individualistas. ${ }^{17}$

Afinal, sem uma atuação transnacional cooperativa nenhum projeto de civilização vindoura será exitoso. A solidariedade também é imprescindível como razão de existência, fonte de legitimação e objetivo maior a ser alcançado por esse novo modelo de governança. ${ }^{18}$

16 Sobre este tema são sempre muito oportunas as lições de Boaventura de Souza Santos, quando adverte que a nova governança não pode ser o triunfo da legalidade ou do projeto neoliberal que silencia conceitos como: transformação social, participação, contrato social, justiça social (SANTOS; GARAUTI, 2007. p. 33, 36).

17 Maurice Hauriou explica que a base do Estado Moderno é formada por princípios individualistas e que as declarações de direitos também contribuíram para a construção da ordem jurídica individualista. In: HAURIOU, Maurice. Princípios del Derecho Público y Constitucional (Trad. Estudio preliminar, Notas y Adiciones: Carlos Ruiz del Castillo). Granada: Camares, 2003. p. 68 e ss.

18 Conforme destaca Gabriel Real Ferrer, a solidariedade é o fundamento de qualquer grupo humano e também do Estado, indispensável para a coesão social e para gerar a indispensável sensação de pertencimento entre os cidadãos. Cf (REAL FERRER, 2003, p. 123-179). Também é enfático ao afirmar que a eficácia das soluções depende da alteração 
Embora não seja o objetivo específico deste trabalho teorizar acerca da forma pela qual serão institucionalizadas ou implementadas as novas estratégias de governança, desde logo é possível antecipar que a governança transnacional não depende apenas da criação de sofisticadas e complexas instituições. Fundamentais são as atitudes concretas voltadas à proteção efetiva de bens jurídicos de vocação planetária, tanto por parte de instituições e organismos - locais e transnacionais -, como também pelas autoridades. A XV Conferência da Mudança do Clima da ONU (COP15), em muitos aspectos e para alguns países, foi apenas um compromisso retórico de natureza política.

A questão climática é um tema que vai além da dimensão ecológica, pois diz respeito também ao desenvolvimento, à sustentabilidade e à própria justiça intergeracional.

O impacto direto da redução de emissão de gases geradores de efeito estufa no desenvolvimento é uma variável que deve ser analisada considerando principalmente a capacidade específica de cada país e os benefícios que em médio e longo prazo podem ser alcançados.

A relação direta com a sustentabilidade, entendida enquanto imperativo ético tridimensional que abrange aspectos sociais, econômicos e ecológicos, também parece inconteste. Assim como a sua direta relação à ideia de justiça e equidade ambiental, especialmente a justiça intergeracional.

A questão climática, ao ser tratada como uma demanda transnacional, requer uma nova estratégica de governança para a definição concreta de metas, objetivos e pautas de condutas aos Estados.

Historicamente, a primeira conferência a abordar ampla e formalmente a questão climática, foi a ECO/92. Esta foi a primeira vez que o tema sensibilizou estudiosos e autoridades de todo o globo para a adoção de instrumentos e medidas concretas em prol do planeta Terra.

da organização social do planeta e que a solidariedade deve ter aplicação generalizada não apenas na perspectiva ética mas também como princípio jurídico formalizado (REAL FERRER, 2002). 
Como principal resultado da ECO/92, e sem desconsiderar valiosas contribuições de encontros anteriores, ${ }^{19}$ foi elaborada a ConvençãoQuadro das Nações Unidas sobre Mudança Climática, que estabeleceu um conjunto amplo de diretrizes e objetivos a serem implementados pelos países para a estabilização das concentrações de gases de efeito estufa na atmosfera num nível que impeça uma interferência antrópica perigosa no sistema climático e que possa afetar negativamente e ameaçar os ecossistemas naturais e a própria humanidade.

Após a ECO/92, os encontros e as tratativas objetivando a criação de um instrumento específico para definir padrões de emissões prosseguiram até 1997, quando então foi editado o Protocolo de Kyoto. Apesar de muitos países, a exemplo dos Estados Unidos como maior emissor de poluentes do globo, não terem aderido ao tratado, este documento internacional significou um importante avanço no tratamento das questões climáticas.

A Convenção-Quadro das Nações Unidas reconhece que a natureza global da mudança do clima requer a maior cooperação possível de todos os países e sua participação em uma resposta internacional efetiva e apropriada, conforme suas responsabilidades comuns, mas diferenciadas e respectivas capacidades e condições sociais e econômicas.

Ao declinar os princípios, a Convenção-Quadro das Nações Unidas procurou estabelecer como dever a proteção do sistema climático em benefício das gerações presentes e futuras da humanidade com base na equidade e em conformidade com suas responsabilidades comuns, de acordo com as diferenciadas capacidades dos Estados nacionais.

Apesar das proposições avançadas acima citadas, a operacionalização das medidas para proteção do equilíbrio climático implica na definição de formas de financiamento, assunto que não está disciplinado adequadamente nas convenções anteriores.

Por isso, um dos destaques da discussão sobre o clima em Copenhague foi a proposta que consiste na criação de um fundo ambiental transnacional para combater a deterioração provocada pelo efeito estufa que seria

${ }_{19}$ Conference on the Changing Atmosphere - Toronto (Canadá), outubro de 1988; e IPCC’s First Assessment Report em Sundsvall - Suécia, agosto de 1990. 
financiado por um imposto de até $1 \%$ sobre o valor das importações. O novo tributo incidiria sobre produtos que causam dano ao ambiente e que têm alto impacto na formação do efeito estufa, como os derivados do petróleo, por exemplo. Como contrapartida, os produtos ecologicamente sustentáveis, como é o caso dos equipamentos de energia solar e combustíveis à base de biodiesel e etanol, estariam isentos da incidência fiscal.

Seria, mutatis mutandis, uma releitura transnacional conjugada dos princípios materiais da justiça ambiental e tributária segundo os quais a responsabilidade tributária deveria obter de cada um segundo as suas possibilidades, para atender a cada um conforme suas necessidades em termos de combate aos fatores que provocam o desequilíbrio climático no planeta.

Na XV Conferência da Mudança do Clima da ONU (COP15), além da natural dificuldade na articulação de amplo consenso, considerandose a diversidade de interesses e intenções, dois pontos fundamentais evidenciaram a insuficiência do modelo atual de regulação internacional da questão climática, quais sejam: a forma de financiamento e a definição das responsabilidades concretas de cada Estado. Tudo ainda agravado pela impossibilidade do estabelecimento de medidas impositivas aos países.

Este quadro aponta para a necessidade do estabelecimento de novas estratégias democráticas de governança da regulação climática para o acesso e a adequada gestão dos bens ambientais e o compartilhamento solidário de responsabilidades enquanto grande desafio do milênio. Segue a mesma linha de raciocínio de Boaventura de Sousa Santos, quando defende que o movimento democrático transnacional é o único sinal de esperança na luta contra a iniquidade do mundo em que vivemos (SANTOS, 2006, p. 1).

\section{Conclusões}

Entre os novos desafios, gerados pela intensificação da globalização e pela crise ecológica multidimensional - que caracterizam a sociedade de risco, hipercomplexa e policonflitiva - merece especial destaque a questão climática. Essas novas demandas propiciam também uma crise 
de governança global sem precedentes e torna oportuna e necessária a implementação de novos modelos de gestão e regulação.

A crise de governança decorre tanto pela obsolescência do modelo estatal nacional, limitado pelas fronteiras territoriais, como também pela insuficiência do sistema e da lógica jurídica do direito internacional clássico para a eficaz tutela planetária do meio ambiente, especialmente no que diz respeito ao risco futuro e à tutela das futuras gerações com relação ao clima.

Apesar dos avanços propiciados pela inserção de postulados ecológicos nas suas Constituições, há ainda um deficit substancial na implementação das normas ambientais apenas pelos Estados constitucionais modernos. Tudo exatamente pela falta de políticas, estratégias de ação e normas com maior força cogente, dotadas de eficácia transnacional. Estratégias de regulação desta natureza são medidas imprescindíveis para o estabelecimento de deveres jurídicos que contribuam com a reversão do atual cenário de intensa degradação ecológica geradora de impactos diretos no equilíbrio climático.

Dessa forma, é imprescindível o desenvolvimento de novas estratégias de governança transnacional ambiental que sejam capazes de articular atitudes solidárias, inclusivas, democráticas e cooperativas, e de agregar as pessoas, instituições e Estados na luta pela proteção de bens e valores imprescindíveis para assegurar, principalmente para as futuras gerações, uma vida digna, sustentável e promissora.

Em síntese: o futuro desafia a consolidação de novas formas de governança, estruturadas como uma grande teia de proteção do planeta, regidas por princípios ecológico-sociais e que assegurem alternativas e oportunidades democráticas mais inclusivas, participativas e emancipatórias e tenham como preocupação garantir um mundo melhor para as futuras gerações. Só com novas estratégias globais de governança, baseadas na cooperação e na solidariedade, é que será possível assegurar um futuro com mais justiça e sustentabilidade (BODNAR; CRUZ, 2008, p. 51-59). Esse é o provável grande desafio a ser enfrentado. 


\section{Referências}

BACHELET, M. Ingerência ecológica: direito ambiental em questão. Lisboa: Instituto Piaget, 1995.

BECK, U. Liberdade ou capitalismo. Tradução de Luiz Antônio Oliveira de Araújo. São Paulo: Littera Mundi, 2001.

BELINKY, A. Éramos caubóis, somos astronautas. Revista Veja. n. 2145. São Paulo: Editora Abril, dez. 2009.

BODNAR, Z.; CRUZ, P. M. Pensar globlamente y actuar localmente: el Estado Transnacional Ambiental en Urich Beck. Revista Aranzadi de Derecho Ambiental, n. 1, Alicante, Espanha, p. 51-59, 2008.

CORDINI, G. Diritto ambientale comparato. Padova, 1997.

CRUZ, P. M. Repensar a democracia. Revista Lex - Jurisprudência STF. São Paulo: Lex. Jurisprudência do Supremo Tribunal Federal, v. 366, p. 5-27, 2009.

CRUZ, P. M.; BODNAR, Z. La transnacionalidad y la emergencia del Estado y del Derecho Transnacionales. Barcelona: Revista V-Lex, v. 4, 2009.

CRUZ, P. M.; BODNAR, Z. A transnacionaldade e a emergência do Estado e do Direito Transnacionais. In: CRUZ, P. M.; STELZER, J. (Org.). Direito e transnacionalidade. Curitiba: Juruá, 2009.

CRUZ, P. M.; CADEMARTORI, L. H. O princípio republicano: aportes para um entendimento sobre o interesse da maioria Revista de estudos constitucionais, hermenêutica e teoria do direito, v. 1. São Leopoldo: UNISINOS p. 87-96, 2009.

HABERMAS, J. A constelação pós-nacional. Trad. de Márcio Selligmann-Silva. São Paulo: Litera Mundi, 2001.

HAURIOU, M. Princípios del derecho público y constitucional. (Trad. Estudio preliminar, Notas y Adiciones: Carlos Ruiz del Castillo). Granada: Camares, 2003. 
JAQUENOD DE ZSÖGÖN, S. Derecho ambiental sistemas naturales y jurídicos. Barcelona: Dykinson, 2008.

LEFF, H. Saber ambiental: sustentabilidade, racionalidade, complexidade, poder. Trad. Lúcia Mathilde Endlich Orth, Petrópolis: Vozes, 2005.

LE PRESTRE, P.; MARTIMORT-ASSO, B. A reforma na governança internacional do meio ambiente: os elementos do debate. In: VARELLA, M. D.; BARROS-PLATIAU, A. F. (Org.). Proteção internacional do meio ambiente. Brasília: Unitar/UniCEUB/UnB, 2009.

LOPORETA ROTA, D. Los princípios de derecho ambiental. Madrid: Editorial Civitas, 1998.

MARTÍN MATEO, R. La revolución ambiental pendiente. In: PIÑAR MAÑAS, J. L. Desarrollo sostenible y protección del medio ambiente. Madrid: Civitas, 2002.

MARTÍN MATEO, R. Tratado de derecho ambiental: recursos naturales. v. 3. Madrid: Editorial Trivium, 1997.

MIGLINO, A. Uma comunidade mundial para a tutela do ambiente (a Paulo Márcio Cruz). Revista Archivo Giuridico, v. CCXXVII - Fascículo IV. Roma: Mucchi Editore, 2007. (Editada por Filippo Serafini; título original: Una comunitá mondiale per la tutela dell' ambiente (a Paulo Márcio Cruz)). Disponível em: <http://www.mucchieditores.it>. Acesso em: 20 abr. 2010.

REAL FERRER, G. La construcción del Derecho Ambiental. Revista Aranzadi de Derecho Ambiental. Pamplona: Espanha, n. 1, 2002, p. 73/93. Disponível em: <http://www.dda.ua.es/ documentos/construccion_ derecho_ambiental.pdf $>$.p. 25. Acesso em: 20 jan. 2009.

REAL FERRER, G. La solidariedad en el derecho administrativo. Revista de Administración Pública (RAP), n. 161, maio/ago. 2003. SANTOS, B. S. A escala do despotismo. Revista Visão. Coimbra: Universidade de Coimbra, 2006. 
SANTOS, B. S.; GARAUTI, C. A. R. (Org.). El derecho y la globalización desde abajo: Hacia uma legalidad cosmopolita. Barcelona: Anthropos, 2007.

VILLASANTE, Tomas. Las democracias participativas. Madrid: Ediciones HOAC, 2003.

YOUNG, O. R. Teoria do regime e a busca de governança global. In: VARELLA, M. D.; BARROS-PLATIAU, A. F. (Org.). Proteção internacional do meio ambiente. Brasília: Unitar/UniCEUB/UnB, 2009.

Recebido em: 25/01/2010 Revisado em: 22/04/2010 Aprovado em: 29/05/2010 